\title{
A COMUNICAÇÃO COTIDIANA ENTRE PROFESSORAS E FAMÍLIAS NO PROCESSO DE COMPARTILHAMENTO DA EDUCAÇÃO DA CRIANÇA PEQUENA NA EDUCAÇÃO INFANTIL*
}

Maria Aparecida Guedes Monção

\section{Introdução}

Muito se tem discutido a respeito da necessidade de se garantir que as instituições de Educação Infantil se configurem em espaços que respeitem os direitos fundamentais das crianças. Em que pese o fato de em sua origem a creche ter a marca da filantropia - e, portanto, a ausência da responsabilização do Estado -, na década de 1980 os movimentos de mulheres, junto com outros movimentos populares, defendiam a integração da creche ao sistema educacional, como direito de todas as crianças de 0 a 6 anos. A atuação desses movimentos resultou na inserção do tema na Constituição Federal de 1988 (CF/1988), que estabelece como dever do Estado "o atendimento em creches e pré-escolas às crianças de 0 a 5 anos" (BRASIL, 1988, art. 208, IV); e como um direito de trabalhadoras e trabalhadores, na zona rural e urbana, "a assistência gratuita aos filhos e dependentes desde o nascimento até 5 anos de idade em creches e pré-escolas" (BRASIL, 1988, art. 7, XXV).

Entretanto, foi em 1996, com a promulgação da Lei de Diretrizes e Bases da Educação Nacional (LDB/1996) (BRASIL, 1996), que ocorreu um amplo processo de mudança nas instituições de Educação Infantil. Situada ao lado da pré-escola, a creche passou a ser considerada como a primeira etapa da Educação Básica e, conforme disposições da LDB/1996, "tem como finalidade o desenvolvimento integral da criança até cinco anos de idade, em seus aspectos físico, psicológico, intelectual e social, complementando a ação da família e da comunidade" (BRASIL, 1996, art. 29).

${ }^{*}$ DOI - 10.29388/978-65-86678-02-4-0-f.149-168 
As Diretrizes Curriculares Nacionais para a Educação Infantil (DCNEI) somam-se a esses marcos legais e orientam a implementação de políticas e práticas para a primeira etapa da Educação Básica, pautadas na especificidade da educação de bebês e de crianças pequenas, que se deve materializar por meio da centralidade das brincadeiras e das relações sociais no currículo da Educação Infantil, da necessária articulação entre cuidado e educação e do seu compartilhamento entre professoras e famílias.

De acordo com o artigo $6^{\circ}$ das DCNEI, os princípios éticos, políticos e estéticos norteiam as instituições de Educação Infantil e, ao considerá-los, as propostas pedagógicas devem assumir a responsabilidade de "compartilhar e complementar a educação e cuidado das crianças com as famílias" (CONSELHO NACIONAL DE EDUCAÇÃO, 2009b, art. $\left.7^{\circ}, \mathrm{II}\right)$.

Compartilhar a educação da criança pequena entre famílias e professoras é tarefa complexa, que envolve valores e interesses muitas vezes divergentes, provocando tensões e conflitos revestidos de emoções e sentimentos ambivalentes acerca da criança, da família e da professora. De acordo com os estudos referentes a essa temática (HADDAD, 1993; MONÇÃO, 1999; VITÓRIA, 1997), as concepções de família, de maternidade e do papel da mulher são elementos centrais para a compreensão dessa relação, visto que a propagação do ideário da família nuclear em que o homem assume o papel de provedor material e a mulher é a responsável pelos cuidados para com os filhos ancora-se numa visão idealizada da maternidade como elemento inato à mulher e como responsabilidade privada de cada família. De acordo com Haddad (1993), ao se pautar em um único padrão de família, a creche ocupa o lugar de substituta materna, com a intenção de suprir a ausência da mãe, o que provoca inúmeros conflitos entre profissionais e famílias e dificulta a efetivação da Educação Infantil como política pública no campo educacional.

A efetivação de uma política pública educacional para a primeira infância pautada nos direitos das crianças pequenas exige permanente diálogo entre os adultos responsáveis por sua educação - fa- 
mílias e professoras ${ }^{1}$-, no sentido de definir objetivos comuns e partilhar experiências. A participação das famílias nas instituições de Educação Infantil, nesta perspectiva, é considerada um dos critérios para avaliar a qualidade da creche ou pré-escola (BRASIL, 2006; CORRÊA, 2001; SILVA, 2011). A constituição de uma relação dialógica com as famílias, para além de favorecer a qualidade do trabalho desenvolvido, deve ser uma das finalidades da instituição. Segundo o Parecer acerca da revisão das DCNEI, o atendimento integral dos direitos da criança "requer que as instituições de educação infantil, na organização de sua proposta pedagógica e curricular, assegurem espaços e tempos para a participação, o diálogo e a escuta cotidiana das famílias, o respeito e a valorização das diferentes formas em que elas se organizam" (CONSELHO NACIONAL DE EDUCAÇÃO, 2009a, p. 13).

Corrêa (2001, p. 52) considera a participação das famílias no contexto educacional das crianças como uma "necessidade também para a escola. Isto porque, [...] mesmo que ela contasse de fato com o 'melhor' corpo de profissionais, a escola não é a única agência ou instituição responsável pela educação das gerações mais novas de uma sociedade".

No âmbito internacional, os estudos concernentes à Educação Infantil italiana (BONOMI, 1998; FORTUNATI, 2009; GHEDINI, 1994; SPAGGIARI, 1995) permitem aprofundar o entendimento quanto à importância da parceria entre educadoras, educadores e famílias, ao tomar como pressuposto central a participação de crianças, educadoras, educadores e famílias na gestão dos serviços para a primeira infância, baseado num sistema de permanentes interações, com significado político, cultural e educacional (GHEDINI, 1994). Segundo Spaggiari (1998, p. 99-100), “A ideia condutora é, portanto, a de uma creche compreendida como trama de relações comunicativas, como rede insaciável de dinâmicas sociais, como sede de processos formativos, integrados e compartilhados pelas famílias, pelos educadores e pelas crianças".

\footnotetext{
${ }^{1}$ Considerando que a maioria que atua diretamente com as crianças são mulheres, optei por escrever o termo no feminino.
} 
A cultura de participação presente na Educação Infantil italiana é um exemplo do poder público que assume o cuidado e a educação da criança pequena como sua responsabilidade, em parceria com a família, considerando a criança como sujeito de direitos e a maternidade como responsabilidade social não apenas da mãe: “a ideia de buscar soluções coletivamente, como é feito em muitos programas municipais de educação infantil na Itália, é contrária à noção popular de que as famílias tendem a ver os problemas em termos restritos e privados" (SPAGGIARI, 2016, p. 101).

Bonomi (1998) analisa a trajetória do relacionamento entre educadores, educadoras e pais na rede italiana de creches, destacando que, além de considerarem a creche como um contexto de socialização coletivo, as políticas públicas de Educação Infantil na Itália, especialmente na Região Norte, buscaram delinear sua especificidade na "atenção colocada sobre os aspectos relacionais na educação da criança” (BONOMI, 1998, p. 162).

Nessa direção, as pesquisas a respeito da Educação Infantil italiana assinalam a necessidade de se vincularem necessidades e direitos das crianças, educadoras(es) e famílias, a fim de construírem relacionamentos que alicercem um atendimento de qualidade e o compromisso de toda a sociedade quanto à responsabilidade na educação das crianças pequenas, considerando a Educação Infantil como um projeto da comunidade (BONDIOLI; MANTOVANI, 1998; FORTUNATI, 2009).

De maneira geral, a legislação e as pesquisas apresentadas a respeito da relação entre creche e família brasileiras e italianas contribuem para a compreensão da Educação Infantil como um dos contextos de socialização da criança pequena e como um direito das crianças e suas famílias, que deve ser efetivado por meio de uma política pública democrática, que garanta a educação da criança em parceria com a família. Nesse sentido, o propósito deste texto é problematizar as formas de comunicação entre professores e famílias a partir de análise de algumas situações observadas no cotidiano de um Centro de Educação Infantil (CEI) paulistano. 
O conteúdo apresentado é fruto de uma tese de doutorado (MONÇÃO, 2013), cujo objetivo centrou-se na análise das relações entre famílias e profissionais da Educação Infantil, no processo de compartilhamento da educação da criança pequena, com vistas a identificar a especificidade da administração educacional nesse segmento. A pesquisa empírica foi realizada ao longo de dois anos, em um CEI da rede municipal de São Paulo, que atende crianças de 0 a 4 anos. Os dados foram coletados por meio de observação participante, análise documental e entrevistas semiestruturadas com onze professoras, um professor, três coordenadoras pedagógicas, uma diretora, dois agentes técnicos de educação, um agente escolar, uma auxiliar de limpeza, uma auxiliar de cozinha, uma supervisora de ensino e dezoito famílias.

A organização dos dados foi realizada a partir de três eixos analíticos: 1) a relação entre professoras e crianças; 2) a relação entre professoras e equipe de gestão; e 3) a relação entre professoras e destas com as famílias. As categorias analisadas no eixo relação entre educadores e famílias foram: 1) formas de comunicação com as famílias; 2) compartilhamento da educação e cuidado da criança; 3) participação das famílias no conselho do CEI.

O presente capítulo integra conteúdo da categoria "Formas de comunicação com as famílias", e está organizado em três partes. A primeira apresenta uma síntese das formas de comunicação identificadas no CEI pesquisado; em seguida, analisam-se alguns elementos que dificultam a comunicação cotidiana e, por fim, as considerações finais.

\section{A comunicação entre educadores e famílias no CEI Anália Franco ${ }^{2}$}

Cada unidade educacional de Educação Infantil compõe um grupo diferente de pessoas, com trajetórias de vida e formação muito distintas. Para atingir aos objetivos educacionais, é preciso que esse conjunto de pessoas tenha objetivos e propósitos comuns

\footnotetext{
${ }^{2}$ Os nomes do CEI, das crianças, das professoras e dos familiares apresentados no texto são fictícios.
} 
e utilize o diálogo como instrumento primordial para a constitui ção de relações democráticas.

[...] o diálogo deve ser entendido como algo que faz parte da própria natureza histórica dos seres humanos. É parte de nosso progresso histórico do caminho para nos tornarmos seres humanos [...] o diálogo é uma espécie de postura necessária, na medida em que os seres humanos se transformam cada vez mais em seres criticamente comunicativos. O diálogo é o momento em que os humanos se encontram para refletir sobre sua realidade tal como a fazem e re-fazem [...]. (FREIRE; SHOR, 1986, p. 64)

Por meio do diálogo, é possível qualificar a comunicação entre famílias e professoras no dia a dia, com vistas a constituir uma relação profícua que permita aproximação e integração entre o contexto familiar e o educacional.

A análise do Projeto Político-Pedagógico da instituição pesquisada revelou que a articulação com as famílias e com a comunidade é expressa de maneira generalizada no documento, com o objetivo de promover a parceria, tendo como eixo a melhoria do processo educativo. Para isso, são propostas ações que viabilizem maior participação da comunidade e das famílias, no sentido de reconhecer o CEI como espaço educativo, tais como: atitude conjunta na adaptação da criança; envio de bilhetes a respeito da reunião de pais com antecedência; promoção de eventos (palestras sobre Saúde e "Dia da família na escola”); incentivo à participação no Conselho e na Associação de Pais e Mestres (APM); envolvimento das famílias no projeto "Plano de metas".

O controle das inscrições e liberação de vagas disponíveis é realizado pela Secretaria Municipal de Educação (SME), por meio de um sistema informatizado. A primeira comunicação entre a unidade educacional e a família ocorre normalmente quando esta é informada a respeito da vaga e comparece à unidade para efetuar a matrícula da criança. Apesar da importância desse momento para o estabelecimento de vínculo entre professoras e famílias, em muitas unidades da rede 
ele se configura apenas como uma atividade cartorial, sem a preocupação em acolher de maneira mais cuidadosa as famílias, que, em sua maioria, apesar da satisfação com a liberação da vaga, sentem-se inseguras e ansiosas pelo fato de deixarem seus filhos na instituição.

Os primeiros contatos da família com a unidade de Educação Infantil devem configurar-se como espaços privilegiados para a troca entre docentes e familiares, de maneira a permitir o conhecimento da proposta educativa do CEI, os profissionais que atuarão junto às crianças, assim como a forma de educar das famílias. Conhecer as famílias é um dos pressupostos para efetivar um bom início de relacionamento. De acordo com Ghedini (1994, p. 270),

[...] ao estabelecer contato com os pais, é preciso, por um lado, criar uma situação aberta à comunicação, estar pronto para ouvi-los e entender seu plano educacional (todos os pais têm planos para seus filhos explícitos ou não apesar de geralmente terem um não explícito, enquanto as creches devem explicitar o seu); por outro lado, o contexto social, cultural e econômico das famílias deve ser levado em consideração.

Todavia, as observações no cotidiano do CEI revelaram o contrário: parece que a SME trata esse período inicial apenas como um dos aspectos do calendário escolar, sem inseri-lo como diretriz pedagógica e garantir estrutura e apoio às professoras para efetivarem a qualificação desse momento. Por se tratar de um elemento fundamental para compor a política de Educação Infantil do município, faz-se necessário garantir condições objetivas para que as professoras e a equipe de gestão planejem e viabilizem as matrículas de maneira cuidadosa, e utilizem as informações e os relatos das famílias como elementos auxiliares no processo de planejamento do acolhimento e inserção das crianças e suas famílias no início do ano letivo, de modo a inaugurar de forma positiva o relacionamento.

As formas de comunicação com as famílias mais utilizadas na instituição são: as conversas entre professoras e famílias nos momentos de entrada e saída, a comunicação via agenda e as reuniões. 
Os momentos de entrada e saída das crianças nas unidades de Educação Infantil são ocasiões ricas em possibilidades para promover o encontro entre equipe de gestão, professoras, famílias e crianças. São espaços privilegiados para a troca de informações e o aprofundamento de vínculos, apesar de ocorrerem em um curto espaço de tempo. Entretanto, a despeito de seu potencial para favorecer ações de aproximação, podem-se observar situações de tensão - atraso de familiares, problemas de saúde das crianças, adultos sem autorização para retirar a criança da creche, dentre outros que foram tratados apenas com soluções emergenciais, sem um aprofundamento dos reais motivos que provocaram tais situações.

Cada criança possui uma agenda e sua utilização é uma das estratégias de comunicação mais comuns nas unidades de Educação Infantil da rede pesquisada. Os professores dedicam boa parte de seu tempo a fazer registros diários que, na maioria, constituem-se de informações gerais referentes ao dia da criança na unidade, observações de seu comportamento, informes das atividades ou regras de funcionamento da instituição. Entretanto, apesar de ser um mecanismo para ampliar a interlocução com os familiares, inúmeras situações observadas demonstraram que esse instrumento pode também dificultar a aproximação entre professoras e famílias, especialmente quando o recado aborda temáticas ligadas ao comportamento ou a acidentes com as crianças, e a forma da redação provoca mal-estar e tensão entre professoras e famílias.

As reuniões entre familiares, professoras e equipe de gestão são outra estratégia importante para aprofundar o processo de compartilhamento da educação das crianças pequenas. É um momento propício também para estreitar os laços entre as famílias, socializar a maneira como educam seus filhos, seus dilemas e inquietações a respeito da educação das crianças, compartilhar experiências, reflexões e ampliar suas concepções do papel parental, da infância e da política pública de Educação Infantil.

No CEI pesquisado, as reuniões ocorrem em duas modalidades: 1) reunião geral, com todas as famílias, equipe de gestão e profes- 
soras, realizada normalmente no início do ano, e em momentos em que é preciso informar e encaminhar questões de ordem coletiva como: calendário da unidade, reposição de dias de atendimento; 2) reuniões específicas de cada agrupamento, que ocorrem bimestralmente, ora no período da manhã ora no período da tarde, com revezamento das professoras ${ }^{3}$ na coordenação e definição da pauta.

Por dois anos consecutivos, foram observadas as duas modalidades de reuniões, que ocorriam de forma muito similar. O momento inicial da primeira reunião do ano é conduzido pela diretora e pela coordenadora pedagógica; na sequência, os familiares dirigem-se às salas em que suas crianças estudarão, para a reunião com as professoras.

O segundo momento da reunião é realizado nas salas em que as crianças ficam diariamente, e é coordenado pelas professoras. Em apenas uma das salas observadas foi realizada uma dinâmica, em que as professoras solicitavam que as famílias escrevessem quais eram suas expectativas com relação ao CEI. Nessa sala, as professoras acolhiam afetivamente as famílias e suas perguntas, tentando tranquilizá-las e demonstrar a qualidade do atendimento.

Os informes das reuniões ressaltam exclusivamente as responsabilidades das famílias com relação à: pontualidade nos horários de entrada e saída das crianças; autorização para retirada das crianças; importância da higiene, saúde das crianças; organização da mochila das crianças; leitura diária da agenda e participação das famílias no Conselho de CEI.

Destaca-se que os informes nas reuniões são os mesmos durante todo o ano, mas são passados como se fosse a primeira vez. Inexiste uma ação compartilhada entre as partes, apenas a responsabilização das famílias com relação a seus deveres. Talvez pelo fato de não haver um processo de matrícula que envolva e dialogue com as famílias, de maneira a conhecer sua forma de educar, tais informações parecem que não fazem muito sentido para elas ou não condizem com suas condições de efetivá-las, sem contar que essas regras são constan-

\footnotetext{
${ }^{3} \mathrm{O}$ período de funcionamento do CEI é integral e as professoras dividem-se em dois turnos de trabalho.
} 
temente retomadas por meio de cartazes em frente às salas das crianças.

No que tange às reuniões, pode-se constatar que, apesar de sua importância - especialmente a primeira reunião do ano letivo para a constituição do vínculo entre famílias e educadores, o tom predominante nesses encontros é prescritivo, com ênfase exclusiva nas normas, que são repetidas continuamente, sem que se promova reflexão a respeito de seu significado para a educação da criança. São regras elaboradas para as famílias e não com elas. Porém, a ausência de reflexão a respeito disso impede os educadores de perceber que, introduzidos dessa maneira, os informes em nada contribuem para aproximar as famílias.

Nas reuniões específicas por agrupamento, há uma regularidade em iniciar o encontro com a leitura de um texto, seguida por uma dinâmica de grupo e informes. Depois, as professoras relatam o trabalho desenvolvido, descrevem os projetos, socializam as produções das crianças - desenhos e, semestralmente, os relatórios de avaliação. Essa modalidade possibilita promover um ambiente participativo e proximidade maior das famílias. Na maioria das vezes, as famílias ouvem muito e pouco se expressam. Quando falam, sempre fazem perguntas da rotina, alimentação e do comportamento das crianças, especialmente se batem em outras crianças, indagações às quais as professoras respondem prontamente.

Importante assinalar que nas entrevistas com as professoras e famílias, além das reuniões descritas acima, houve destaque para o encontro intitulado "Dia da família no CEI", como agregador das famílias. Trata-se de uma atividade prevista para ocorrer semestralmente, cuja proposta é realizar ações que envolvam as professoras, as crianças e as famílias. Nesses eventos há sempre uma produção coletiva: desenho, pintura da cortina da sala, confecção de brinquedos. Os familiares apreciam muito realizar tais atividades com as crianças, e nas entrevistas teceram muitos elogios a esse encontro, destacando sua importância, especialmente para seus filhos. A despeito de seu caráter pontual, esse momento demonstra ser muito frutífero para potenciali- 
zar a relação com as famílias, talvez por seu formato de oficina, em um ambiente descontraído e alegre, e reconhecimento positivo da presença e participação dos familiares.

\section{Encontros e desencontros na comunicação entre famílias e educado- $\operatorname{ras}(e s)$}

Ao longo do período de permanência na unidade educacional, foi possível constatar muitas dificuldades na comunicação entre educadores e famílias, o que provoca diversos conflitos e dificulta o compartilhamento da educação da criança. Situações como mordidas entre as crianças, atraso no momento de entrada ou saída, sumiço de roupas e objetos das crianças (que são colocados por engano pela professora em outra mochila e não são devolvidos pela família da criança que as levou), ausência das famílias nas reuniões, questões de saúde das crianças, são motivos para desencadear desentendimentos entre profissionais e familiares.

Tomando como exemplo uma situação casual ocorrida no CEI, um pai ficou nervoso ao ser informado que, em função da falta de energia, a creche não promoveria o atendimento naquele dia. Inconformado com a situação, ofendeu a auxiliar técnica de Educação e chutou um brinquedo que estava no corredor. Diante do ocorrido, as professoras do agrupamento do berçário, por iniciativa própria, colocaram um cartaz em frente a uma sala com a transcrição do artigo 331 do Código Penal, segundo o qual o desacato ao servidor público, no exercício de sua função ou em razão dela, pode acarretar prisão de seis meses a dois anos, ou multa.

Pode-se inferir que essa situação revela a fragilidade da comunicação estabelecida entre a instituição e os familiares, pois o tom ameaçador do aviso pouco favorece a promoção do diálogo ou evita situações similares. Situações como essa, além de requererem uma abordagem individual com o responsável pela agressão - o que foi feito pela diretora da unidade educacional - demandam uma reflexão dos profissionais, com o objetivo de identificar os motivos que provocaram tal circunstância e pensar em estratégias dialógicas que permitam 
refletir, junto com as famílias, formas de comunicação que solucionem os conflitos de maneira pacífica.

Nessas situações, as crianças ouvem e acompanham as manifestações das professoras e das famílias, realizadas em sua presença, na maioria das vezes sem nenhum cuidado. A criança fica "invisível” para os adultos, que pouco se atentam aos seus sentimentos, esquecendo-se de que elas aprendem ao observar e participar das interações, as quais podem contribuir positiva ou negativamente para a constituição da imagem que elas constroem de si, de sua família e dos educadores.

De acordo com Spaggiari (1998, p. 100), as famílias, educadoras(es) e crianças são

[...] tão indivisíveis na sua recíproca integração, e tão inseparáveis nas suas relações, que o bem-estar e o desconforto de um dos três não é apenas correlacionado, mas interdependente do bem-estar ou desconforto dos outros dois sujeitos. Este conceito de interdependência induz a considerar que a creche só pode ser pensada e organizada como local de "relacionamento a três", onde a presença e o protagonismo das famílias é tão essencial quanto a presença e o protagonismo das crianças e educadores.

Como já assinalado na Introdução, a existência de conflitos entre famílias e educadores tem sido evidenciada em vários estudos, desde a década de 1980 (HADDAD, 1993; MELLO, 1987; MONÇÃO, 1999; VITÓRIA, 1997), e a permanência dessas tensões ao longo de mais de três décadas revela que os embates presentes no cotidiano do CEI trazem em si componentes sociais, políticos e ideológicos e, portanto, são merecedores de atenção e constante reflexão para lidar com sua complexidade.

Galvão (2004, p. 190) considera o conflito "inerente à dinâmica social e constitutivo da vida psíquica”. A autora identifica três tendências na forma como a escola aborda os conflitos: “1) camuflá-los; 2) considerar que são provocados por fatores externos ao contexto escolar; 3) vivenciar a eclosão dos conflitos como uma indicação ou de- 
monstração de um fracasso completo da ação educacional." (GALVÃO, 2004, p. 194).

Nessa direção, para garantir a constituição de um ambiente favorável à educação das crianças, é fundamental que os embates entre educadoras/es e familiares sejam considerados elementos importantes para reflexão na formação das professoras e nos encontros com as famílias- como também nas diretrizes pedagógicas da rede e ensino , visto que, quando os conflitos não são tomados como objetos de reflexão, dificilmente se garante bem-estar para as crianças e educadores e é produzido um ambiente tenso, em nada fortalecendo o potencial construtivo dos conflitos.

Um dos elementos evidenciados na análise dos depoimentos das professoras e na observação das reuniões com as famílias, que interfere na qualidade da comunicação e serve como impeditivo para a promoção de uma relação colaborativa, refere-se à visão das professoras a respeito das famílias. De maneira geral, pode-se afirmar que nesta visão ainda predominam aspectos depreciativos. Quando perguntadas, nas entrevistas, a respeito dos motivos que justificavam a adoção, pelas famílias, de posturas classificadas pelas docentes como "inadequadas" com seus filhos, era comum as professoras utilizarem termos como "desleixo" e/ou "falta de vontade", demonstrando uma postura de julgamento e desconhecimento do contexto social e cultural das famílias. Por outro lado, as entrevistas com as famílias evidenciam com unanimidade a visão positiva que possuem a respeito do CEI e, especialmente, das professoras.

Há uma compreensão generalizada de que as famílias repassam suas responsabilidades para o CEI; entretanto, essa proposição deve ser analisada com cautela, pois diversos estudos têm demonstrado que as famílias se preocupam, sim, com seus filhos e não deixam de exercer suas funções. No caso do CEI pesquisado, ao que tudo indica, há uma questão de gênero, pois na maioria das vezes as professoras, ao expressarem essa visão, referem-se à displicência das mães, reforçando o modelo de que a mulher é a única responsável pela educação das cri- 
anças e desconsiderando os diferentes papéis que as mulheres ocupam na sociedade atualmente.

Como assinalado na Introdução, é preciso lembrar que, ao longo da história, especialmente com a expansão do capitalismo, a mulher ocupou um papel ligado ao âmbito privado, sendo responsabilizada pelos cuidados da casa e dos filhos, como esteio numa estrutura em que o homem se envolveu na esfera pública, com funções políticas e econômicas. Nessa linha, as divisões de papéis eram claras e as crianças e mulheres eram subordinadas ao homem. Entretanto, apesar da disseminação desse modelo, sempre houve diferentes formas de organização familiar, que eram consideradas "fora do padrão" ou "família desestruturada".

A observação de uma reunião de formação continuada para a socialização de um projeto desenvolvido em um dos agrupamentos do CEI é ilustrativa para compreender a visão das professoras acerca das famílias. Ao longo do ano, são realizados projetos utilizando livros de histórias, músicas ou filmagem da rotina das crianças; as professoras enviam tais materiais para as famílias, as quais realizam atividades com seus filhos, registram suas percepções e devolvem para as professoras.

A primeira etapa do projeto apresentado consistia em organizar duas mochilas (uma para os meninos e outra para as meninas, segundo as professoras para otimizar o tempo) com brinquedos relativos ao tema gerador do projeto mensal - animais e um caderno para registro da atividade. As mochilas eram enviadas na segunda-feira e retornavam ao CEI na quinta-feira. Na segunda e terceira etapas do projeto, trocavam-se os objetos da mochila, primeiramente por livros de literatura infantil e depois por massa de modelar. A última etapa consistia em construir um livro da vida.

Ao apresentar esse projeto na reunião, as professoras avaliaram-no positivamente; contudo, as observações com relação às famílias chamaram a atenção, e serão elencadas, a seguir, por meio do registro de trechos da reunião: 
As professoras começaram a apresentação informando as etapas do projeto e contando que, antes de iniciá-lo, realizaram uma pesquisa e constataram que $67 \%$ das mães trabalham. ${ }^{4}$ A professora Jerusa informa ao grupo que deixou para enviar as mochilas por último para os pais que são mais "dispersos" e conta que "o último menino, não voltou nenhum brinquedo, nem massinha. Ela [mãe] mandou dois brinquedos diferentes [dos que foram enviados pelas professoras] e avisou que, se achasse mais, devolvia.” Relatam que são situações desagradáveis e a professora Karin diz: "A mochila das meninas teve que trocar, voltou 'estropiada'." A professora Jerusa complementa: "Alguns, além de demorarem para devolver, quando devolvem não escrevem".

O grupo de professoras aprecia muito o relato do projeto e a professora Suzana diz: "O relato não foi assistencialista, o pedagógico fala mais alto”.

A professora Valentina concorda e diz que um aspecto importante do projeto é que "chama os pais para a responsabilidade", e conta uma situação em que uma mãe lhe perguntou se a criança tomava leite no CEI e ela respondeu afirmativamente; a mãe a informa que em casa seu filho não toma leite. A professora, admirada com a informação, pergunta o motivo, e a mãe responde: "Dá muito trabalho e eu dou Danone". Nesse momento, o grupo dispersa com conversas paralelas, com comentários depreciativos sobre as mães, classificando-as como "permissivas", "sem limites", "que está muito cansada e quer que a criança durma e por isso só serve Miojo para elas", e uma professora afirma: "É pura preguiça!!!"

Mesmo a diretora, que sempre tem uma postura muito acolhedora com as famílias e questiona as professoras quando tecem críticas pejorativas a elas, nesse momento concordou com as docentes e afirmou: "Somos forçados a forçar o pai a assumir a responsabilidade deles". E relatou a experiência que teve com uma mãe que quase não ficava com a filha, devido ao horário de

4 Não foi possível compreender o objetivo de tal pesquisa para o projeto. 
trabalho. Conta que a chamou para uma conversa e solicitou que alterasse seu horário de trabalho para ficar com a filha. E conclui o relato afirmando que considerava muito cômodo para a mãe "ter contato com a criança apenas no domingo".

A professora Lucimar aproveita a fala da diretora e exclama: "Essa é uma visão dos educadores, porque a visão externa [com relação às famílias] é de coitadinha... Assistencialista”. A professora Suzana complementa: "Alguns [pais] falam: 'ai, que bom que ele vai ficar aqui [no CEI]. Vou dormir'."

Pode-se perceber, por meio do relato, a inexistência de problematizações acerca dos motivos que levam as famílias a agirem do jeito que relatam; há uma concordância geral nas críticas às famílias. Ao longo da apresentação do projeto, pouco se atentou aos seus resultados positivos, pois as apreciações foram direcionadas à postura inadequada das famílias e não ao significado do projeto para ampliar a interlocução com os familiares e sua contribuição para a efetivação do compartilhamento da educação da criança. Em contrapartida, nas en trevistas com as famílias, elas enaltecem a iniciativa das professoras e relatam a experiência positiva ao realizarem a atividade proposta em casa, junto com as crianças.

Por meio do acompanhamento desse relato e de outros similares ao longo da pesquisa (MONÇÃO, 2013), constata-se que, muitas vezes, as professoras não se atentam ao potencial dessas ações para aproximação e conhecimento do contexto familiar. A análise das situações-problema de forma superficial e pontual, além de reforçar ideias depreciativas com relação às famílias, expressa uma visão compensatória dos projetos para suprir a falta de interação entre os pais e seus filhos, sem considerar o contexto social, os desafios e os dilemas para articular educação dos filhos e atuação profissional, pautando-se apenas na hipótese da falta de comprometimento das famílias. No entanto, o exame dos problemas identificados pelas professoras, de maneira reflexiva, à luz do contexto social e dos estudos a respeito do tema, poderia promover a compreensão dos motivos que os provocam e as 
possibilidades de envolvimento e sensibilização das famílias para solucioná-los.

\section{Considerações finais}

Para qualificar o compartilhamento da educação da criança e a constituição de uma educação democrática, os detalhes contidos nas formas de comunicação cotidiana entre professoras e famílias devem ser permanentemente repensados, buscando-se ajustá-los aos princípios democráticos e ao respeito ao direito dos seres humanos de serem tratados como cidadãos, com atenção especial às sutilezas desse relacionamento, que, desprovido de análise crítica, acarreta, sem que as professoras percebam, o distanciamento e não a aproximação das famílias, e afeta o bem-estar da criança na instituição.

Ao analisar as formas de comunicação entre educadoras(es) e famílias no CEI pesquisado, verifica-se que um dos desafios para potencializar sua natureza dialógica é a realização de análises sistemáticas acerca da forma como ela se efetiva, tendo como base o diálogo e a negociação, em busca de um maior conhecimento acerca das famílias e suas expectativas, na trilha de uma cultura de partilha de ideias e experiências a respeito da educação da primeira infância.

A boa comunicação é fundamental e deve ser considerada como um aspecto relevante, a ser planejado e discutido permanentemente. As tensões devem ser tratadas por meio de uma reflexão mais ampla e não de forma isolada, de modo a permitir o aprofundamento acerca da maneira como se dá a educação da criança no CEI e na família, enfrentando e aprofundando o debate acerca da especificidade do papel de cada instituição. Por meio do diálogo, é importante identificar a linha tênue que marca o limite entre essas duas instituições, qual é o ponto em que elas se entrelaçam e como delinear estratégias de comunicação que possibilitem a constituição de um relacionamento profícuo entre famílias e educadores.

É preciso reafirmar o sentido da educação pública e o direito dos cidadãos de participar das instituições educacionais. A discussão 
concernente à importância da participação das famílias nas instituições de Educação Infantil deve extrapolar o contexto educacional e somar força com as lutas pela garantia da democracia em nosso país, por melhores condições de vida, extinção das desigualdades sociais e pelos direitos das mulheres à igualdade de oportunidades.

\section{Referências}

BONDIOLI, Anna; MANTOVANI, Susana (org.). Manual de educação infantil: de 0 a 3 anos - uma abordagem reflexiva. 9. ed. Porto Alegre: Artmed, 1998.

BONOMI, Adriano. O relacionamento entre educadores e pais. In: BONDIOLI, Anna; MANTOVANI, Susanna. Manual de educação infantil: de 0 a 3 anos. 9. ed. Porto Alegre: Artes Médicas, 1998. p. 161172.

BRASIL. [Constituição (1988)]. Constituição da República Federativa do Brasil: promulgada e publicada em 5 de outubro de 1988. Brasília, DF, 1988.

. Lei no 9.394, de 20 de dezembro de 1996. Estabelece as diretrizes e bases da educação nacional. Diário Oficial da União, Brasília, DF, 23 dez. 1996.

- Ministério da Educação. Secretaria de Educação Básica. Parâmetros nacionais de qualidade para a educação infantil. $2 \mathrm{v}$. Brasília, DF: MEC/SEB, 2006.

CONSELHO NACIONAL DE EDUCAÇÃO. Câmara de Educação Básica. Parecer CNE/CEB n 20/2009, aprovado em 11 de novembro de 2009. Revisão das Diretrizes Curriculares Nacionais para a Educação Infantil. Brasília, DF, 2009a.

. Câmara de Educação Básica. Resolução nº 5, de 17 de dezembro de 2009. Fixa as Diretrizes Curriculares Nacionais para a Educação Infantil. Brasília, DF, 2009b. 
CORRÊA, Bianca Cristina. Possibilidades de participação familiar e qualidade na educação infantil. 2001. Dissertação (Mestrado em Educação) - Faculdade de Educação, Universidade de São Paulo, São Paulo, 2001.

FORTUNATI, Aldo. A educação infantil como projeto da comunidade: crianças e pais nos novos serviços para a infância e a família: a experiência de San Miniato. Porto Alegre: Artmed, 2009.

FREIRE, Paulo; SHOR, Ira. Medo e ousadia: o cotidiano do professor. Rio de Janeiro: Paz e Terra, 1986.

GALVÃO, Isabel. Cenas do cotidiano escolar: conflitos sim, violência não. Petrópolis, RJ: Vozes, 2004.

GHEDINI, Patrizia Oliveira. Entre a experiência e os novos projetos: a situação da creche na Itália. In: ROSEMBERG, Fúlvia; CAMPOS, Maria Malta (org.). Creches e pré-escolas no Hemisfério Norte. São Paulo: Cortez: FCC, 1994. p. 189-210.

HADDAD, Lenira. A creche em busca de identidade. São Paulo: Loyola, 1993.

MELLO, Ana Maria. Tempo de mudança na creche Vila Praia. Cadernos de Pesquisa, São Paulo, n. 60, p. 79-84, fev. 1987.

MONÇÃO, Maria A. Guedes. Subalternidade ou parceria? Um estudo das representações sociais sobre participação das famílias nas creches. 1999. Dissertação (Mestrado em Psicologia da Educação) - Programa de Pós-Graduação em Psicologia da Educação, Pontifícia Universidade Católica de São Paulo, São Paulo, 1999.

. Gestão democrática na educação infantil: o compartilhamento da educação da criança pequena. 2013. Tese (Doutorado em Educação) - Faculdade de Educação, Universidade de São Paulo, São Paulo, 2013.

SILVA, Ana Tereza Gavião Almeida Marques da. A construção da parceria família-creche: expectativas, pensamentos e fazeres no cuida- 
do e educação das crianças. 2011. Tese (Doutorado em Educação) Faculdade de Educação, Universidade de São Paulo, São Paulo, 2011. SPAGGIARI, Sergio. Considerações críticas e experiências de gestão social. In: BONDIOLI, Anna; MANTOVANI, Susanna. Manual de educação infantil: de 0 a 3 anos. 9. ed. Porto Alegre: Artes Médicas, 1998. p. 96-113.

. A parceria comunidade-professor na administração das escolas. In: EDWARDS, Carolyn; GANDINI, Leila; FORMAN, George. As cem linguagens da criança. Porto Alegre: Penso, 2016. p. 99-106. VITÓRIA, Telma. Representações das educadoras sobre as mães e famílias das crianças da creche. 1997. Dissertação (Mestrado em Ciências) - Faculdade de Medicina, Universidade de São Paulo, Ribeirão Preto, 1997. 